\title{
Application of Multimedia Technology in Music Teaching in Junior High School
}

\author{
Ge Chuchu ${ }^{1 *}$, Li Jia ${ }^{2}$ \\ ${ }^{1}$ Nanjing Private Yuying Foreign Language Middle School, Nanjing, China; International College, \\ Krirk University, Thailand \\ ${ }^{2}$ College of Music, Shanxi Normal University, Shanxi, China \\ *Corresponding author
}

Keywords: multimedia, junior high school, music

Abstract: Under the background of the information age, education has gradually shown a new development journey and a new looks, and has begun to develop in the direction of modernization. In the diversified technical system, multimedia, as an important technical module, plays a significant supporting and supporting role in the whole field of education. The rational application of multimedia to music classes can improve the entire teaching environment and at the same time promote the overall implementation of education work efficiently. This article mainly analyzes the function and application of multimedia as an advanced method in the field of music teaching in junior high school.

\section{Introduction}

In the process of developing music teaching in the new era, teachers need to focus on the functional advantages of the subject itself such as aesthetic appreciation and innovation. In addition, in line with the education standards for optimizing the music classroom, teachers need to innovate on the specific teaching environment and teaching mode. Teachers should take a correct view of the development trend of modernization, and rationally implement and apply multimedia to the music classroom, which can also enhance the overall relaxed classroom atmosphere and help students to efficiently complete related learning explorations.

\section{Analysis of the role of multimedia in music teaching in junior high schools}

\subsection{Activate interest in learning}

Different from the preaching classroom atmosphere in the past, the application of multimedia can effectively change the learning attitude of students in the classroom. It can lead students to deepen their understanding of the cultural connotation of music in the process of intuitive observation and comprehensive experience of the situation. This will ensure that the constructed music materials are more intuitive and show a certain degree of interest, so as to activate students' comprehensive learning interest in the field of music. The most important thing is that students can always maintain a strong subjective initiative in the process of participating in curriculum exploration and learning, 
which has an important impact on the stimulation of students' awareness of learning and the further improvement of learning motivation.

\subsection{Improve the learning environment}

In the past, the lecture-style classroom was relatively boring in terms of atmosphere, which was not conducive to the active activation of students ${ }^{[1]}$. The application of multimedia can effectively improve the entire classroom environment. With the support of the courseware, the music knowledge that was originally abstract and boring is presented in a more flexible way. In this way, students can effectively feel and understand the specific musical connotation and perceive related music rhythms and melody in a relaxed and active classroom atmosphere. Promoting students' subjective awareness of music exploration can also ensure that students' learning quality is effectively improved.

\subsection{Improve classroom effectiveness}

The teaching reform in the new era emphasizes that teachers must implement high-efficiency and high-quality strategic thinking when they fully develop music teaching. The application of multimedia contributes to the in-depth implementation of the above goals. Through the comprehensive integration of courseware, it is possible to further improve the teaching resources and specific presentation methods of the music classroom. In addition, it also effectively activates the students' appreciative thinking. At the same time, it can also inspire students to build a strong enthusiasm for music singing learning and outreach training, so that they can complete related learning tasks with fuller emotions. This will ensure that all teaching links in the music classroom can be effectively implemented, and further enhance the comprehensive learning quality of students in the field of music.

\section{The application analysis of multimedia in music teaching in junior high school}

\subsection{Integrate music cultural resources with the help of multimedia}

As we all know, multimedia is an important educational tool derived from the support of information carriers. In the context of the current modernization reform, multimedia has shown a wide range of promotion. At the same time, multimedia plays an important supporting role in improving the music teaching environment and realizing effective classroom implementation ${ }^{[2]}$. In the process of teaching planning and setting with the help of multimedia, teachers need to pay attention to the overall integration of cultural resources. Allow students to master a richer and more specific musical cultural background when participating in music lessons, and let them conduct a more in-depth appreciation on this basis. Encourage students to form a correct concept of music appreciation under the premise of a comprehensive understanding of music culture. At the same time, it can also promote it to obtain a more complete and specific reserve of music knowledge.

Taking "Prairie Singing" as an example, teachers can collect classic grassland songs during teaching, and then refine cultural resources based on the author's creative background and the described grassland customs. Then set up the multimedia courseware scientifically and present it effectively in the classroom. Let the students further think about the cultural meaning behind the musical works in the process of observation. At the same time, students are encouraged to scientifically explore relevant music elements with the goal of learning national music culture as the guide. Not only that, when teachers implement music teaching, they also need to pay attention to the resource integration function of multimedia in traditional national music culture, for example, to 
effectively collect a certain representative traditional music culture. Effectively refine and integrate musical works from ethnic minority areas. Then let the students explore the customs of ethnic minorities and the specific style of music in the process of learning.

\subsection{Use multimedia to construct music appreciation scenes}

In a music class, the appreciation module occupies an important part, and it also significantly affects the development of students' aesthetic thinking and comprehensive appreciation ability. In the process of leading students to appreciate learning, teachers need to correctly view the learning aid function of multimedia as advanced technology software. Comprehensively integrate relevant cultural knowledge related to musical works and specific musical works, and construct multimedia courseware scientifically ${ }^{[3]}$. Then, integrate it into the classroom, leading students to deepen their understanding of the connotation of music through independent thinking and in-depth association in a good atmosphere of appreciation. At the same time, in the process of appreciating teaching, it is also possible to construct exploratory task scenarios through multimedia. Teachers should lead students to conduct in-depth explorations around the specific rhythm, style and emotional characteristics of musical works. With the assistance of multimedia, students conduct group interactive exchanges and discussions on the collected music cultural resources, so as to improve the depth and level of understanding and understanding of music appreciation.

For example, teachers can lead students to conduct independent appreciation and exploration around the "national prestige and national spirit". Throughout the teaching process, the teacher collects music works that fit the theme of the country's prestige and soul through the comprehensive multimedia integration method. The red culture and patriotic songs are fully integrated, and then an exploratory appreciation topic is constructed. Teachers lead students to appreciate and analyze more independently on the premise of a comprehensive understanding of the rich music cultural background and common sense reserves. Throughout the learning process, students are encouraged to develop reasonable interactions and exchanges to strengthen students' understanding of the connotation of music. At the same time, it can also ensure that the constructed music classroom is more open and fuller of vitality and the advantages of multimedia scene rendering and thinking guidance can be fully utilized.

\subsection{Use multimedia to set up fun music games}

For junior high school students, music shows a certain degree of fun, and its vivid characteristics are more obvious ${ }^{[4]}$. In the process of teaching practice, teachers need to rely on the assistance of multimedia to scientifically construct interesting and diverse game activities, so that students can get a good learning atmosphere. In the process of participating in the game, students can deeply understand the rich connotation of music, and at the same time can realize the comprehensive cultivation of students' music aesthetic thinking and appreciation ability. In the process of game setting, teachers need to use the contextual functions of multimedia to scientifically construct rhythmic game activities. Play relevant music works for the students, and then let the students complete the rhythm game exploration activities autonomously, driven by the rhythm and melody. In the process of listening to music, students use their physical performance to improve their coordination ability, and at the same time, they can also promote themselves to form a good sense of rhythm.

For example, teachers can collect related music works around "Spring's Footsteps" and then dynamically present them in a multimedia manner. After that, teachers should encourage students to perform rhythmic performances freely. In the whole process, teachers need to provide students with a wider range of free creation and performance space to activate students' comprehensive 
appreciation and innovation momentum.

\subsection{Carrying out the teaching of music singing based on multimedia}

Singing is an important carrier for organizing junior high school students to reasonably transform their basic music knowledge into practical skills. In the process of actual teaching, teachers need to focus on the basic norms of students' music and give full play to the advantages of multimedia. Then, the teacher sets up the specific singing teaching environment reasonably, gives the students the correct guidance, and prompts them to complete the relevant singing learning tasks more effectively. First of all, in the demonstration teaching module, teachers need to change the traditional teacher-oriented demonstration singing mode. In order to improve the accuracy and standardization of music singing demonstration teaching, teachers can play the demonstration audio of music singing for students through multimedia courseware and other methods, and then give the students correct guidance. Only in this way can we encourage students to master the specific pronunciation of music, and do a good job in the standard processing of tones and timbre. At the same time, it can also encourage students to accurately master the specific musical accompaniment, and then participate in the singing activities in a standardized and orderly manner.

For example, it is possible to rationally teach singing around the "clouds of the hometown", and first collect more standardized demonstration videos and audios through multimedia. Then lead the students to feel the rhythm of the music in the process of listening, as well as the concrete manifestation of the singing method. After that, the teacher should lead the students to actively participate in relevant training in the process of summarizing and summarizing. Not only that, teachers can also use multimedia methods to deeply analyze and decompose the elements contained in the process of singing music songs, so that students can understand specific music theories, and then participate in practice singing training in a standardized manner.

\subsection{Using Multimedia to Implement Musical Moral Education}

In the junior high school stage, music is not only an important subject of aesthetic education, but also its moral function. Therefore, teachers need to effectively utilize the auxiliary advantages of multimedia, and obtain richer cultural resources of music and moral education through the comprehensive integration of resources. Then, the teacher will infiltrate the multimedia into the classroom reasonably, leading the students to explore in depth. In the process of learning, students can master a wealth of moral connotations. Students will also develop good character in the process of participating in learning.

For example, teachers can focus on the theme of "inheriting the red classics", collect red song resources in multiple directions and all aspects, and then construct special activities for learning patriotic themed songs in the form of courseware. Teachers lead students to gradually form a good sense of patriotism in the process of listening and singing. At the same time, it can also encourage students to actively learn the national spirit behind the red songs, so that in the future growth process, they can take serving the motherland as their mission, study earnestly and continuously improve them. Not only that, but also through multimedia courseware, we can fully integrate excellent traditional folk music cultural resources. Integrate the resources of the more distinctive music works of ethnic minorities to construct appreciation topics. Teachers should lead students to actively participate in research and do a good job in all-round exploration of resources, so as to encourage students to further deepen their understanding of national music culture and form a good sense of inheritance. 


\subsection{Use multimedia to set up multiple expansion training}

In the entire music teaching, teachers need to comprehensively analyze the students' music literacy development needs, and standardize the establishment of diversified outreach training activities. Only then can students scientifically transform their accumulated theoretical knowledge and experience into practical and applied skills, so that they can gain deeper attainments in the field of music. Throughout the entire process of outreach training practice, teachers need to use multimedia correctly to optimize the design of specific outreach training content and practice forms. So as to provide students with a good use of space, activate the students' music literacy, and at the same time can encourage students to feel the charm of music. And in the future study, students can use advanced technology and equipment to independently carry out music innovation and creation.

For example, with the support of multimedia equipment, teachers can encourage students to listen to the rhythm and melody of music and create lyrics on their own. At the same time, teachers can encourage students to give full play to the creative support functions of multimedia, and guide students to create and edit independently in the way of computer music. While activating students' innovative thinking, it can also promote a deeper understanding of music culture, and generate a lifelong learning hobby and strong kinetic energy.

\subsection{Use multimedia to optimize music teaching evaluation}

In the current field of music teaching, classroom evaluation is a key link. It can be said that it determines the quality of music classroom teaching and also relates to the construction of students' music learning literacy. Therefore, in the process of implementing evaluation, teachers need to correctly understand the processing functions of modern carriers and integrate multimedia into the evaluation process. Teachers should show students' comprehensive learning performance in the music classroom, and then construct an independent evaluation and reflection mechanism. Teachers should give intuitive feedback based on the actual performance of students, and lead students to analyze and summarize together, so that students can form a clear understanding of their own comprehensive learning ability in the process of intuitive experience. Then, on this basis, continuously adjust and improve their own learning status, master more abundant learning methods and skills, and improve students' music learning ability.

\section{Points for attention in multimedia teaching in junior high school Music}

\subsection{Insist on teacher-led and student-oriented}

Multimedia shows a strong application function advantage in the current education environment, but in the process of practical application, it is necessary to further clarify the correct concept of education. We should grasp the opportunity of multimedia teaching application and coordinate the relationship between teachers and students in the environment of multimedia education. In the entire process of multimedia teaching planning and implementation, teachers need to further clarify their dominant position and set up the content of multimedia courseware scientifically. Not only that, the students' autonomous learning status needs to be highlighted. Teachers need to lead students to explore relevant music knowledge autonomously and consciously under the support of multimedia.

\subsection{Appropriate application and optimized content settings}

In the process of using multimedia to build a new type of music classroom in the future, teachers need to uphold the strategic principle of effective combination of tradition and modernity. While 
using multimedia to build an intuitive and relaxing music classroom atmosphere, the traditional teaching mode of explanation needs to be retained. Teachers need to conduct a reasonable penetration of the more important and difficult music knowledge, and lead the students to make a comprehensive analysis. At the same time, teachers help students to break through the difficulties of difficult points through the support of multimedia.

\section{Conclusion}

As mentioned above, multimedia has been widely promoted and applied in the current education field, and it can also optimize and improve the overall teaching environment. In order to deepen the implementation of aesthetic education at the junior high school stage, teachers need to set up music teaching activities in a standardized manner. On the premise of fully understanding the specific teaching goals and development requirements, teachers should strengthen the scientific application of multimedia. Then, on this basis, teachers should strive to build a new and efficient music classroom learning environment, so that students can achieve further divergence of aesthetic thinking in the process of participating in learning. At the same time, it can also encourage students to complete related tasks and explorations with strong motivation throughout the music class.

\section{References}

[1] Zhou Feng-mei, The Application of Multimedia in Junior Music Teaching, The Science Education Article Collects, 2020 (12): 153-154-188

[2] Qiu Jing. The Application of Multimedia Technology in Music Teaching in Junior High Schools. Northern Music, 2018, 38 (09): 207.

[3] Tu Hai-hua. Analysis of the Introduction of Pop Music Based on Junior Music Teaching.Modern Communication, 2017 (17): 150-151.

[4] Feng Wei. The use of multimedia in the teaching of music in junior high schools to motivate students. Popular Science, 2017 (01): 13.

[5] Yin Jian-qiang.The advantages and production considerations of multimedia courseware in junior high school music teaching. Science and Technology Innovation Herald, 2016, 13(33):151-152.

[6] Wang Jing-na. Reflections on the Current Situation of Multimedia Use in Music Teaching in Junior High Schools, China Educational Technology \& Equipment, 2016 (09): 122-123. 